\title{
The Swiss Virtual Campus: Present Situation and Challenges
}

\author{
Bernard Levrat \\ University of Geneva, Switzerland, \\ Chair of the Swiss Virtual Campus (SVC) Commission
}

Key words: Virtual Campus, Distance Learning

\begin{abstract}
The Swiss Federal Government is ready to fund a special program for developing a Swiss Virtual Campus during the 2000-2003 funding period. The projects supported will originate from teachers and involve several institutions. The use of common tools will be encouraged. A unique process of evaluation and accreditation is proposed. Although the SVC is a development project, it will closely follow developments for accessing digital documents, for using platforms and tools for personalized learning, and for renewing pedagogy.
\end{abstract}

\section{MOTIVATIONS}

Switzerland is a small country with a number of universities separated by short distances but knit tightly together by an excellent electronic network, shown in Figure 1.

By tradition, the nine universities and the two Federal Institutes of Technology have developed their teaching and their research to a large degree independently of each other. Recently, growing requests for contributions from the Federal State have called for more coordination. All initiatives that promote such coordination are welcomed.

Decision-makers and teachers alike are worried about changes that global access to Internet resources will bring to education. They are aware that small-scale experiments do not scale up easily. Many teachers would like to take advantage of the new information and communication technologies; they are using e-mail, newsgroups, web pages, and popular software to modernize their communications with their students, but some are also 
interested in participating in larger schemes to produce material that would be competitive with what is bound to appear on the market.

Every four years, all Swiss higher education institutions and the federal government must engage in a budget planning exercise for the next four years. For the period 2000-2003, they were asked to forecast an increased role for Information and Communication Technologies (ICT) in teaching and learning; they all responded positively, although in different ways. In addition to estimating budgets the Federal Institutes of Technology and several universities started support centers for pedagogy, multimedia and software production. These will play a key role in implementing the Swiss Virtual Campus (SVC).

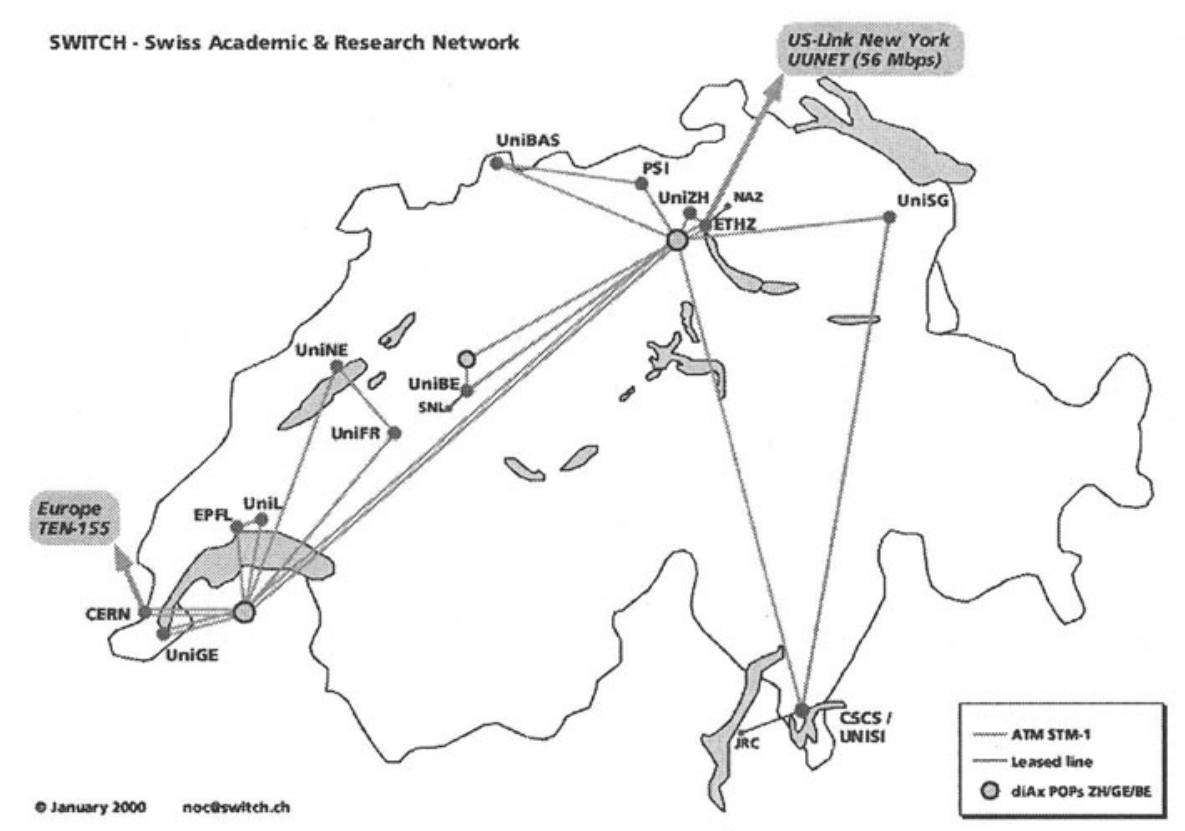

Figure 1. Electronic networking of Swiss Higher Education Institutions. (C)2000, noc@switch.ch

The group of experts, which I headed from 1995 to 1998, contributed to this perception. It tried to produce a clear, understandable proposal that would address the questions of pedagogical design, production, evaluation, and accreditation in the best possible way while promoting strong cooperation among the different institutions and commitment to use the materials once they had been produced. The Swiss government followed our 
recommendations and expects to see significant changes in higher education as we deliver what we promised.

\section{A SHORT HISTORY OF THE SVC'S ORIGINS}

In 1994, a member of the Swiss Parliament asked the government to launch an initiative to implement a generalized Distance Learning program. The Parliament accepted the motion and I was asked to chair a group of experts commissioned to prepare a report on opportunities for "open and distance learning" in Switzerland, with a view to using ICT in universitylevel education both for existing curricula and for lifelong learning. Our report, which was accepted, concluded that it would be inappropriate to finance a new Swiss institution dedicated to open and distance learning and recommended instead that Swiss universities be part of a plan to offer courses in both face-to-face and distance modes.

In 1997, the same group of experts was asked by the Swiss University Conference (SUC), to study the impact of ICT on learning at the university level and to propose a plan of action for the 2000-2003 financial period. The group chose to work under the name of FU.NT (Formation Universitaire et Nouvelles Technologies). Its first proposal was to create and maintain a web site $^{i}$ covering all ICT-related projects in Swiss Higher Education. It was enacted at the University of Fribourg with the support of the Swiss Federal Office for Education and Science (OFES) and the SUC. The full text of the reports in French and in German can be found on this site.

Following similar studies in most OECD countries, the report concluded that institutions of higher education must evolve to take advantage of ICT in order, in turn, to change their approach to teaching and learning. Due to the special Swiss situation with many universities in a relatively small territory, these institutions were asked to cooperate more closely with each other, preferably at the level of their basic activities - research and learning without building complex administrative superstructures.

In the fall of 1997, the FU.NT group proposed an initiative to establish a Swiss higher education learning network by creating a Swiss Virtual Campus. The existing institutions (Federal Institutes of Technology, Polytechnic Schools and Universities) which today require the presence of students, would be encouraged to rethink some of their courses to make them Internet-accessible to their own students and to students from other institutions. A student registered in one university would be able to take for credit courses that are offered on the Internet by another Swiss institution of higher learning. 
Rather than waiting for such courses to become available through uncoordinated efforts, it was proposed to finance projects that would meet certain criteria and promise to produce the intended course material. The quality of the courses will be guaranteed by an accreditation procedure.

This proposal was accepted by the SUC, which submitted it to the Swiss Government to be included in the preparation of the 2000-2003.

\section{THE SVC PROPOSAL}

In its message to Parliament concerning the funding of Higher Education for the period 2000-2003, the Swiss Government included a credit of SFr 30 million for funding the Swiss Virtual Campus with the following objectives:

a) to promote collaboration between institutions - higher education networks

b) to entice teachers to explore a new pedagogical dimension - learner centric model

c) to encourage the development centers to become producers of high quality learning material - competitiveness of the Swiss higher education establishment.

The projects that will be jointly funded by the universities and by this program (the Federal Institutes of Technology and the Polytechnics will join with their own resources) will have to abide by the principles of the "Swiss Virtual Campus" which are summarized in the five following criteria:

1. favor cooperation between higher education establishments (traditional Universities, Swiss Institutes of Technologies, and Technical Universities);

2. highlight a clear pedagogical objective;

3. participate in the selection and use of common tools on stable platforms;

4. present a realization plan with evaluation criteria;

5. obtain from the start a contribution from the institutions interested in the project with the promise to integrate its use and maintenance into their normal planning once the development is finished.

Financing will be granted on a competitive basis, the best projects being selected according to the above criteria and a necessary diversity of subjects. 


\section{CURRENT STATUS AND PLANS FOR IMPLEMENTATION}

The final vote by the Swiss Parliament is due in October 1999 and none of the funding will be available before January 2000. Nevertheless, a number of steps are being taken, with very limited means, to prepare for starting the projects with as little delay as possible. A high-level commission has been established to ensure communication with the different partners; a steering committee will supervise the selection of projects resulting from a call for proposals also being prepared; finally, a list of possible common software tools is being established.

\subsection{The Commission "Campus virtuel suisse" (CCVS)}

First of all, the universities must understand their role and involvement in the plan. Even with the best administrative structure in place, the SVC will not have a project to support at all if groups of teachers from the same discipline do not get together to submit proposals. The role of this particular commission of the SVC is to approve and disseminate the "Call for proposals". Individual commission members, representing rectorates or presidencies, are responsible for making sure that good projects receive the necessary local support from their institution.

\subsection{Steering Committee}

Answering questions from Parliamentary commissions on how the project would be managed, OFES pledged to appoint a steering committee of 5 to 7 members including one or two international experts.

This committee will organize the evaluation of the proposals, propose a list of selected projects, prepare contracts to be signed by project leaders and partners and monitor the projects' conformity with the stated objectives and time table. Milestones will be established for prototyping the first module, for the first evaluation, for production, for field trials, and for final assessment.

\subsection{Choosing and using common software tools}

To develop interactive and innovative learning modules for this project, the management wants to select a set of integrated tools-or, at the least, a set of coherent tools-to accomplish most of the operations necessary in this new context. 
To be acceptable, such a set of products must offer good portability, be accessible by the end-user from a number of platforms (UNIX, MacOS, Windows), support an adequate character set (Unicode) in all the phases of development and final use of the learning material, involve a high degree of interactivity (with control of response times), and provide good support for sound, images, and animation. Such qualities must be demonstrated by convincing examples, freely accessible to the group during the evaluation period.

It is quite possible that the SVC will have to cope with more than a single product to satisfy different types of applications. Products that show exceptional qualities for some aspects, but do not fulfill all the conditions, could also be considered.

\subsubsection{Management of students}

This module will include registration and follow-up of students, administrative and academic records, management of bills, and reminders and warning through e-mail. It will also look after login procedures including personal authentication, distinction between authors (several levels) and learners. It will provide working groups and cooperative work management: bulletin boards, forums, listservers attached to modules.

\subsubsection{Development of pedagogical material}

We are looking for tools to support the design of modules to achieve a pedagogical objective, as well as tools for developing the modules themselves (including automatic code generation from the specifications), including a good version manager.

The system will offer uniform and ergonomic graphical interfaces, tools for the efficient creation and management of multimedia (video on demand server, for example), and easy access to other digital resources (URLs, simulators, demonstrators, databases, etc.).

\subsubsection{Exchange of material with traditional teaching situations}

The popularity of the system will be enhanced if it also facilitates the production of good traditional lecture material derived from the interactive material and the improvement of existing presentations through, for example, vocal annotation of lecture notes. 


\subsubsection{Support of learners' activities}

Facilities will be available to copy all or part of the material while adding personal notes, with due respect to the authors' copyright.

Group activities will be encouraged with chatrooms, sharing common screens (whiteboards), and computer conferencing.

When necessary, distance tutoring will be possible with e-mail, telephone, or teleconferencing.

\subsubsection{Support of evaluation procedures}

Graphical tools to trace the history of the students' progress through the modules are desirable. We want detailed timing information about where students spend their time, diagnosis of blocking points, and reports on the success/failures ratios of different tests.

Global reporting, including reporting on face-to-face activities, will also be available.

\subsection{Motivating the different actors}

An information day organized in Bern on July 1 by the SUC attracted over 200 people. Twenty of them would like to lead a project and over sixty wish to be partners. Since that day, requests for information have been accumulating in my e-mail. Most often, they ask for financial details and advice about how to get their own institutions to commit the necessary resources. Much work remains to clarify all these issues. Meanwhile, some of these potential leaders or partners could lose their motivation.

\section{CHALLENGES}

Even with the full support of federal and local authorities, steering the project is not going to be easy due to important changes continually being introduced by technology, research in pedagogy, and improved understanding of man-machine interaction.

\subsection{Choosing among what is currently available}

The choice of environment(s) must be based on consensus. We are presently engaged in evaluating of what exists commercially and what cooperative efforts would best fulfill the requirements of 4.3 with currently 
available hardware and software. Guessing the range of possibilities that instructional delivery systems will offer in two years time is impossible.

\subsection{Integrating new developments}

Having a common set of tools does not mean excluding new developments. The SVC will follow closely the results of the European Union $5^{\text {th }}$ Framework Programme , which expects results "to improve multimedia authoring, design and production systems for handling radically new combinations of highly visual and interactive media forms, including 3$\mathrm{D}$, virtual reality, and broadband content. Expected benefits to be demonstrated include greater usability, functionality and productivity, as well as cross-media integration and new multi-platform publishing and broadcast applications. New distributed production processes and systems, new work flow procedures such as real-time tele-collaboration and new uses of interactive multimedia should be validated, with the active involvement of all actors concerned from production to distribution and use". The SVC must be able to include these new developments as they attain an acceptable level of maturity.

\subsection{Redefining the role of libraries in higher education}

In any discipline, the university's role is to give students opportunities to form their judgments by drawing on different sources. In addition to discussions with assistants and colleagues, seminars by invited speakers contribute to this goal, but one of the most familiar ways is to browse in the library, consulting books one can borrow and journal articles that one can photocopy.

What will happen to that facility in a virtual campus setting? It is quite important that distance learning is not restricted to offering only a single point of view, but, instead, keeps its users curious and motivated to access a variety of sources such as those discussed below.

\subsubsection{Catalogs, circulation and interlibrary loans}

Library catalogs have been in machine-readable form for at least twenty years. Accessing them through the Web has become a worldwide practice. It is interesting to look for material related to a given subject, but access to books or journals themselves still requires a trip to a real library, which is not always practicable for the distance learner. A few libraries (ETHICS, the library of the ETHZ, for example) will loan books by surface mail to remote individuals, but the more current practice is to use inter-library loan. It 
should be possible for small local libraries to be recognized and vouch for local users who want to borrow a reference book from a university library.

\subsubsection{Virtual libraries}

Seeing the content of a book in a browser, or importing it, is already in practice. The Bibliothèque Nationale de France, most visible architecturally at its new location on the Seine, has digitized 100,000 volumes, 40,000 of which are free from copyright restrictions and available on the Internet at their web site ${ }^{\text {iii }}$.

Consortia in different countries are digitizing considerable amounts of material. Often, access to the resulting digitized documents is restricted to their members. Various charging schemes for outsiders are under consideration but will not be discussed here.

A library-indexing scheme is needed so that people can choose among all the available resources. As many other digitized catalogs do, RERO ${ }^{\text {iv }}$ (the union catalog of the network of reference and university libraries of the French speaking Swiss cantons) is already indexing stable multimedia materials. "Stable" is opposed here to "transient," the characteristics of references provided by search engines like Yahoo or AltaVista, which may be gone after some time.

\subsubsection{Online scientific journals}

Scientific journals, traditionally available in departmental libraries, are a special case. More and more, these journals exist in an electronic form which researchers prefer to the printed form since they are available on their workstations, have hyperlinks, active cross references, and can be the start of an e-mail exchange with the author.

But these journals are expensive and affordable only by research groups with generous research grants. In the past, printed copies ended up in the libraries after a few months. Now, the archiving of past articles is not always guaranteed and there seems to be no intention of providing them free to a larger community.

Many efforts exist to keep access to scientific journals open, particularly for students and for people from other fields. The economic questions are far from being solved, but acceptable solutions must be found with the cooperation of publishers and university libraries. 


\subsubsection{Other materials}

References to multimedia materials can be found in library catalogs. They contain many references to speeches and video recordings that could be put on a server and delivered on demand provided that the network bandwidth allows it.

\subsubsection{Some examples}

Virtual specialized libraries are already a reality. In addition to the $18^{\text {th }}$ century books from the BNF already mentioned, I would like to draw attention to:

- The Thesaurus Linguae Graecae ${ }^{v}$ (TLG) at the University of California, Irvine, is an electronic data bank of ancient Greek literature from Homer ( $8^{\text {th }}$ century $\left.\mathrm{BC}\right)$ to $600 \mathrm{AD}$ with historiographical, lexicographical, and scholastic texts from the period between 600 and $1453 \mathrm{AD}$

- The WWW virtual library ${ }^{\text {vi }}$, set up and maintained by the WWW consortium, offers a rich coverage of many subjects. I often use it to find additional materials for my lectures on software engineering. "The VL is the oldest catalog of the web, started by Tim Berners-Lee, the creator of the web itself. Unlike commercial catalogs, it is run by a loose confederation of volunteers, who compile pages of key links for particular areas in which they are expert; even though it isn't the biggest index of the web, the VL pages are widely recognized as being amongst the highest-quality guides to particular sections of the web. Individual indexes live on hundreds of different servers around the world. A set of catalog pages linking these pages is maintained at Stanford University (California), by Gerard Manning. Mirrors of the catalog are kept at Penn State University (USA), East Anglia (UK), Geneva (Switzerland) and Argentina.",vii

- The NASA photo gallery ${ }^{\text {viii }}$ is an amazing collection of photographs taken by satellite and freely available on the net. It's worth a try if one has enough bandwidth and disk space to import these wonderful pictures.

\section{KEEPING THE PROMISES}

Concerns about common software tools and the availability of a wide variety of digitized resources should not distract actors of the SVC from its stated objectives, which are to

- produce outstanding multi-lingual material; 
- enrich the current cultural and scientific quality of the learning environment;

- include a high degree of interactivity;

- give students more freedom of choice;

- open the way to life-long learning either for diploma granting curricula or for self-improvement.

It is the steering committee's mission to select the right projects, but the results will depend essentially on the dedication of the groups of teachers trying to transform the way their own discipline is being learned.

Having been associated with the pedagogical design of the modules produced by the leading partner, the other partners will be ideally situated to perform quality control of the final product. Rather than calling in outside experts, they will be in charge to proceed with evaluation in a real distance learning situation. The projects are requested to provide line items in their budget for this specific purpose.

The last step of the process is to include the distance courses produced by the SVC initiative in the normal curriculum. Once the faculty members who teach a given subject at one of the partner institutions accept the SVC course into their curriculum, that course will be accredited. The status of the different projects will be found on the VirtualCampus.ch web site. A single portal will let students see what is available and where the successful completion of an SVC course will earn degree credits.

\section{INTERNATIONAL COOPERATION VS. MARKETING}

We hope that the quality of the material produced will give the SVC label such a value that many projects will vie to gain that label. Although it is clear that all Swiss universities will be entitled to use all the products for free, several models must be studied in order to sustain the SVC beyond the current funding period.

Single modules or suites of modules could be packaged and marketed for individual use. Whether through a private software distributor returning royalties to the institution or through a non-profit organization under the direct control of the SVC, such a scheme should generate enough revenue to develop new courses and produce new marketable modules.

Complete courses could be sold to other organizations-public or commercial-to generate revenues comparable to the above.

The SVC could also enter into consortia that promote the exchange of quality material among its members. If the students like this form of learning 
and if many institutions participate, a sizeable portion of current resources devoted to teaching could be re-invested in transforming institutions of higher learning into a different sort of establishment with a few fixed points-research buildings, consulting and tutoring offices, multimedia libraries - and many virtual locations where students could find most of the material they need. Social life, entertainment, rhythms of studies and exams will have to be rediscovered in a different setting, in the hope that the next generation will not be made only of couch potatoes of a mouse-clicking variety.

\section{RESEARCH ISSUES}

The SVC is a development project; it will not consider funding fundamental research although it recognizes that a number of topics must be studied to determine where the fast introduction of ICT is leading education. This research can only be conducted on an international basis, but local research teams will have to adapt international findings to the special circumstances of a multi-cultural and multi-lingual Switzerland. This role will devolve to the current pedagogy departments existing in a number of the major universities in the country. The relationship between the SVC and the University of Geneva is exposed in a more detailed paper written with D. Peraya $^{\text {ix }}$

It is interesting to pick among the many European programs (see ii) some that are directly related to issues concerning the SVC and that have been mentioned in the FU.NT report as necessary endeavors.

\subsection{Open platforms and tools for personalized learning}

This European Program will emphasize personalized learning in collaborative environments that involve high-quality pedagogic approaches. It addresses the development of re-usable components and a suite of modular building blocks and tools on the basis of an underlying open infrastructure supporting a wide range of flexible learning activities (learning by doing, collaborative, and group learning). It should also address the development of environments that facilitate interaction, including social interaction, between learners and teachers. This should encompass all functionality needed to develop, manage, and deliver courses, and benefits should be sought in terms of pedagogy, cost-effectiveness, service quality, and scalability. The work is expected to be validated in more than one learning setting and specific discipline. It should contribute to on-going standardization activities in open learning architecture and the reusability of learning objects. 


\subsection{European Programme for "The flexible university"}

The stated objective is "to integrate and demonstrate emerging technologies for the flexible university of the future through large-scale experiments in areas promoting European integration, and providing advanced facilities to allow learners to follow a personalized mix of courses, and to interact with teachers and each other in new ways. The work should promote higher-quality re-useable learning material; greater choice for learners through demand-driven course management; more consistent quality-management and more cost-effective online access to university and higher education facilities. To facilitate EU-wide implementation, the research should also address university teaching re-engineering, social and pedagogic requirements, and cost-benefits. The learning context (subject domain, target populations), economic and organizational aspects of learning should be addressed in a focused way. The work should help to set technical and operational standards and to stimulate collaboration with other sectors (e.g., academic-industry links, public-private partnerships)".

\subsection{Other programs}

There is also a limited amount of European funding for studies in pedagogy: "Teaching and Learning with the help of New Information Technology". It is hoped that pedagogy departments in Swiss universities will be associated with the studies and experimentation planned for this program.

"Institutional Planning, Resources and Support Services" are also the subject of many studies by different bodies. One can only worry that they are not in step with the rate of innovation imposed by technology.

\section{THE NEAR-TERM FUTURE}

It is our belief that changes in our higher education system will have to include the active participation of current teachers if the present quality is to be preserved. A large number of these teachers expressed interest in the SVC at different meetings we organized, through e-mail, or through direct inquiries. They are encouraged to form partnerships involving several institutions.

The work on the software tools is advancing rapidly. Several products seem to satisfy the management requirements, but we have not yet found the authoring tools we would like to have. 
In October, we will issue the request for proposals. Letters of intent will have to be in by November 30 and we will try to promote some extra cooperation among similar proposals. Final proposals are due February 29, 2000. We hope to be able to present the first results in Copenhagen at the WCCE 2001 Conference. Meanwhile, we are actively seeking to cooperate with organizations with similar activities and objectives.

\section{ACKNOWLEDGMENTS}

I am grateful to the Swiss authorities for including the SVC proposal in their financial planning and for their direct support during the present preliminary phase.

I wish to thank all the members of the FU.NT group for their invaluable contributions to the ideas which form the basis of the SVC; they are, in alphabetic order: Hans Beck, Physics Department, University of Neuchâtel, Jürg Kohlas and Jacques Monnard, Institute for Informatiks, University of Fribourg, Leonard Lutz, Head of the Didactic Center, ETHZ, Beat Münch, Rectorate, University of Basel, Daniel Peraya, TECFA, University of Geneva, André-René Probst, HEC-Inforge, University of Lausanne, Peter Stucki, MultiMedia Lab, University of Zürich, Jean-Louis Vandries, Continued Education, EPFL. Hans Hänni also from ETHZ replaced Leonard Lutz for the final stages of the report. Mario Ostini was representing OFES and Jean-Marc Barras was delegated by the SUC, which organized the secretariat.

I am also indebted to the participants of the IFIP Joint Working Conference in Madrid" on "The virtual campus: trends for higher education and training" for many enlightening discussions. I learned a lot from Alfred Bork during many years of cooperation between Irvine and Geneva, and finally, I must recognize with gratitude the influence of Stephen D. Franklin through many enlightening discussions and his great help in shaping up this paper.

i

EUROPEAN COMMISSION The "Information Society Technologies" programme of Research, Technology Development \& Demonstration under the 5th Framework Programme, December 998.

iii http://gallica.bnf.fr

iv http://www.rero.ch

v http://www.tlg.uci.edu/ tlg/index.html

vi http://vlib.org 
vii $h$ ttp://www.vlib.org/AboutVL.html

viii http://nssdc.gsfc.nasa.gov/photo_gallery/

ix The Swiss Virtual Campus: History and Perspectives, D. Peraya and B. Levrat, in EMI Educational Media International, Routledge, London, 36, 2, pp.97-109

$x$ The virtual campus: trends for higher education and training, Proceedings of the 1997 IFIP TC3/WG3.3\&3.6 Joint Working Conference, Madrid, Spain, 27-29 November, 1997, Eds. Felisa Verdejo and Gordon Davies 